\title{
Ventricular tachycardia in 4 patients evaluated by programmed electrical stimulation of heart and treated in 2 patients by surgical division of anterior radiation of left bundle-branch
}

\author{
R. A. J. Spurrell, E. Sowton, and D. C. Deuchar \\ From the Cardiac Department, Guy's Hospital, London
}

Four patients with intractable ventricular tachycardia have been studied using His bundle electrograms and programmed electrical stimulation of the heart. A re-entry mechanism occurring in the main bundle-branches has been shown to be the most likely basis for the tachycardias. As a result of the deductions made from the electrophysiological studies, 2 patients underwent section of the anterior radiation of the left bundle-branch during open heart surgery to correct other cardiac lesions, in an attempt to interrupt the re-entry circuit.

The first demonstration of a ventricular tachycardia was made by Lewis in 1909.

Patients with ventricular tachycardia fall into two main groups, those in whom there is serious underlying cardiac disease and those in whom the tachycardia occurs with no gross myocardial abnormality (McGee and Tullis, 1959). In the first more common group of patients the prognosis is generally bad (Cooke and White, 1943), but in the latter the prognosis is more favourable (Adams, 1962; Hair, Eagan, and Orgain, 1962). Considerable discussion has centred around the underlying mechanism of ventricular tachycardias. The re-entry theory has been put forward by many workers, and Wellens, Schuilenburg, and Durrer (1972) demonstrated, in 5 patients with ventricular tachycardia, that an underlying reciprocal mechanism might be the basis for the arrhythmia. They suggested that the reciprocal circuit could lie either in the bundle-branches, Purkinje fibres with or without adjacent myocardium, infarcted or fibrotic tissue, or combinations of these. Using programmed electrical stimulation of the heart in association with intracardiac recordings we have studied 4 patients with ventricular tachycardia in whom evidence was obtained from the study that the underlying mechanism for the arrhythmia was most likely to be caused by re-entry. We also present additional information from these studies which suggests that the reciprocal circuit may be in the main intraventricular bundle-branch

Received 27 April 1973. system, and based on these findings we decided on a new surgical approach to the management of this arrhythmia.

\section{Patients and methods}

Table I illustrates the relevant clinical details concerning the 4 patients.

All 4 patients were admitted while in ventricular tachycardia; Cases $I$ and 4 were in cardiogenic shock on admission. The details of the electrocardiograms obtained during tachycardia are shown in Table 2.

All 4 patients underwent emergency cardiac catheterization with left ventricular angiography and coronary arteriography. In addition, an electrophysiological study was carried out to determine the site and mechanism of the tachycardia. Cases I, 3, and 4 were referred for emergency open heart surgery. Case I underwent mitral valve replacement and resection of an inferior left ventricular aneurysm. She succumbed at operation. Case 3 underwent resection of a large anterior left ventricular aneurysm and section of the anterior radiation of the left bundle-branch (see discussion). Normal sinus rhythm was restored but an adequate cardiac output could not be maintained off cardiopulmonary bypass, and she succumbed. Case 4 underwent mitral valve replacement, a saphenous vein bypass graft to the anterior descending coronary artery, and section of the anterior radiation of the left bundle-branch. $\mathrm{He}$ is alive and well and has had no further tachycardias six months after operation (at the time of writing).

Case 2 was treated initially with intravenous lignocaine and his tachycardia controlled. He has had no further attacks of tachycardia six months later (at the time of writing). 
TABLE I

\begin{tabular}{|c|c|c|c|c|}
\hline $\begin{array}{l}\text { Case } \\
\text { No. }\end{array}$ & $\begin{array}{l}\text { Age } \\
(y r)\end{array}$ & Sex & $\begin{array}{l}\text { Aetiology and clinical } \\
\text { details }\end{array}$ & Drugs \\
\hline I & 46 & $\mathbf{F}$ & $\begin{array}{l}\text { Coronary artery disease, } \\
\text { recent anterior and } \\
\text { inferior myocardial } \\
\text { infarction, mitral } \\
\text { regurgitation, left } \\
\text { ventricular aneurysm }\end{array}$ & $\begin{array}{l}\text { Lignocaine, } \\
\text { digoxin, } \\
\text { frusemide, } \\
\text { potassium } \\
\text { supplements }\end{array}$ \\
\hline 2 & 63 & $\mathbf{M}$ & $\begin{array}{l}\text { Alcoholic cardio- } \\
\text { myopathy }\end{array}$ & $\begin{array}{l}\text { Lignocaine, } \\
\text { procainamide, } \\
\text { diphenyl- } \\
\text { hydantoin, } \\
\text { vitamin } \\
\text { supplements }\end{array}$ \\
\hline 3 & 66 & $\mathbf{M}$ & $\begin{array}{l}\text { Coronary artery disease, } \\
\text { anterior myocardial } \\
\text { infarction, left } \\
\text { ventricular aneurysm }\end{array}$ & $\begin{array}{l}\text { Lignocaine, } \\
\text { digoxin, } \\
\text { frusemide, } \\
\text { potassium } \\
\text { supplements }\end{array}$ \\
\hline 4 & 48 & $\mathbf{M}$ & $\begin{array}{l}\text { Coronary artery disease, } \\
\text { mitral regurgitation }\end{array}$ & $\begin{array}{l}\text { Lignocaine, } \\
\text { diphenyl- } \\
\text { hydantoin } \\
\text { digoxin, } \\
\text { frusemide, } \\
\text { potassium } \\
\text { supplements }\end{array}$ \\
\hline
\end{tabular}

TABLE 2 Details of surface electrocardiograms during tachycardia

\begin{tabular}{lcl}
\hline Case No. & Frontal plane QRS axis & Bundle-branch block \\
\hline I & $-70^{\circ}$ & Right \\
2 & $-40^{\circ}$ & Right \\
3 & $-60^{\circ}$ & Left \\
4 & $+145^{\circ}$ & Right \\
\hline
\end{tabular}

The electrophysiological studies were carried out as follows. Three bipolar catheters were introduced percutaneously through one or both femoral veins. Two catheters were positioned in the right atrium, one for recording the right atrial electrogram and one for pacing the atria. This latter catheter could also be moved to the right ventricle for ventricular pacing. The third catheter was positioned across the tricuspid valve and the His bundle electrogram recorded using the technique described by Scherlag et al. (1969).

All recordings were made on an 8-channel Elema Mingograf 8r. The His bundle electrogram was recorded with the frequency response set at 45-500 cycles/second. Leads I, III, VI, and V6 of the surface electrocardiogram were recorded simultaneously with the intracardiac recordings.

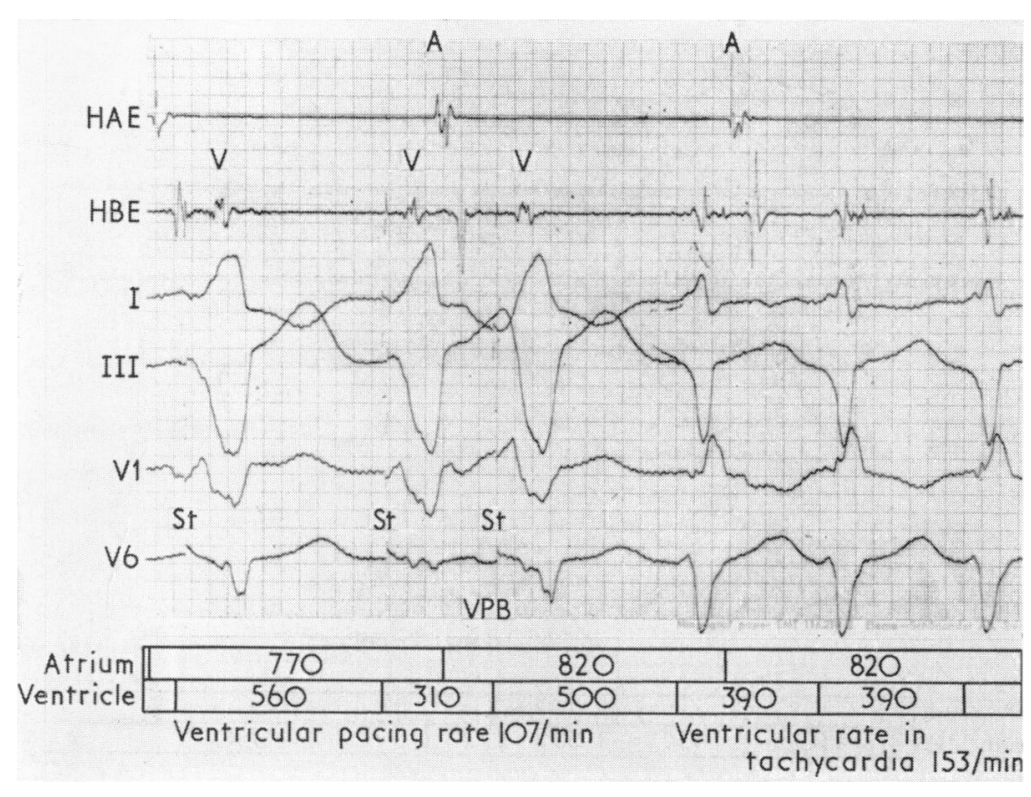

FIG. I Recording from Case I showing initiation of a ventricular tachycardia by a single right ventricular premature beat. $H A E=$ high right atrial electrogram; $H B E=H i$ bundle electrogram; I, III, VI, and V6=surface electrocardiograms; $A=$ atrial depolarization; $V=v e n-$ tricular depolarization; St $=$ stimulus artefact; $V P B=$ ventricular premature beat. Figures shown in the ladder diagram are in milliseconds. 


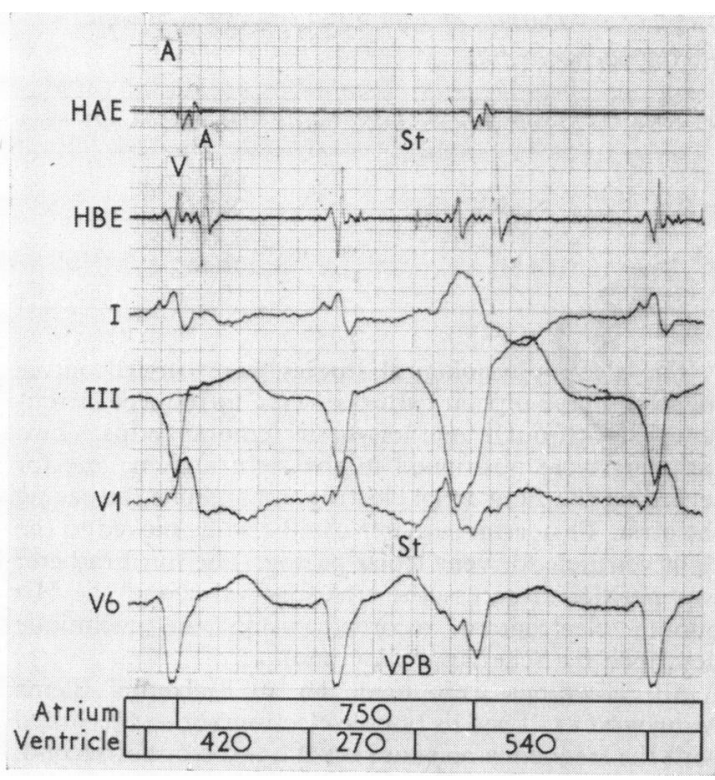

FIG. 2 Recording from Case I illustrating the effect of an induced ventricular premature beat during tachycardia.
A Devices ${ }^{1} 4270$ stimulator was used for atrial and ventricular pacing. The heart was driven at a constant frequency thus preventing any changes in excitability or refractoriness due to irregularities in rhythm. Single or double atrial or ventricular premature beats were delivered after every eighth beat of the basic driven rhythm. A variable delay circuit triggered by either the $R$ wave of the surface electrocardiogram or the right atrial electrogram was used so that the premature beats could be delivered in the cardiac cycle at a preset delay after the preceding driven beat. In each patient the mode of initiation and termination of the tachycardia was studied and the effect of ventricular premature beats on the basic rhythm during tachycardia was studied. The patients in this study were all in tachycardia when admitted and this had to be terminated by a suitable premature beat before the remainder of their stimulation study could be carried out. The criteria that we use for the diagnosis of a reciprocal mechanism rather than a protected ectopic focus in patients with tachycardia are that the tachycardia can be initiated by a suitably timed single or double premature beat, interpolated premature beats induced during tachycardia are followed by pauses less than compensatory, and the tachycardia can be terminated by suitably timed single or double premature beats.

${ }^{1}$ Devices Instruments Limited, Welwyn Garden City, Herts

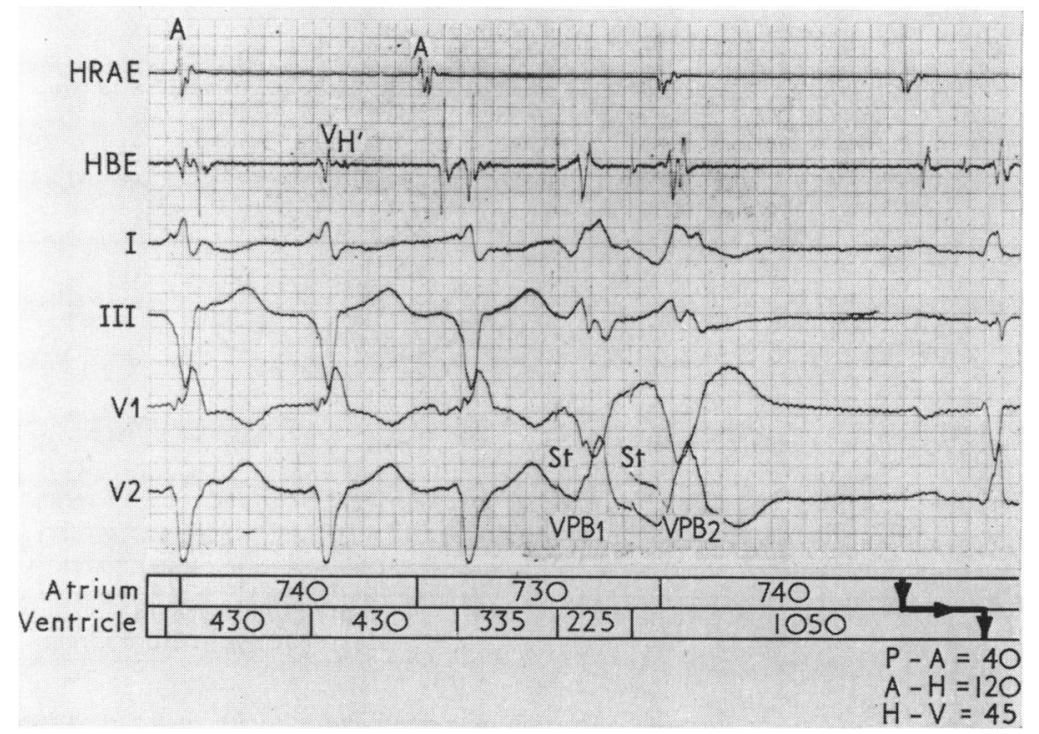

FIG. 3 Recording from Case I showing the termination of a ventricular tachycardia by two ventricular premature beats. $H R A E=$ high right atrial electrogram; $H^{-}=$retrograde His potential. 
A

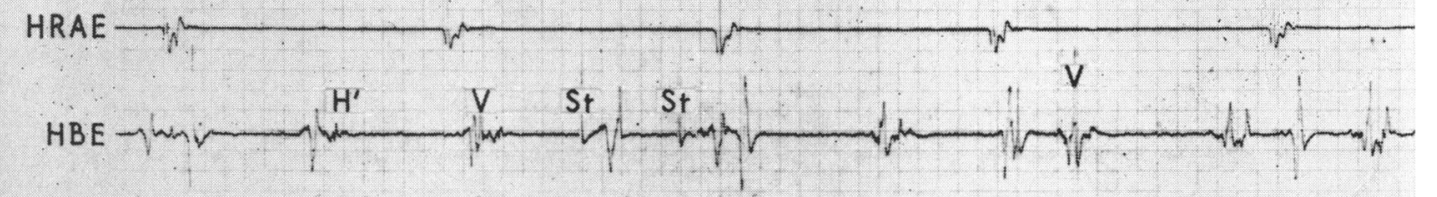

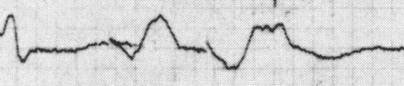

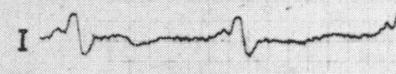<smiles>CCCCCCCCCCCCC</smiles><smiles>CCCCCC</smiles>

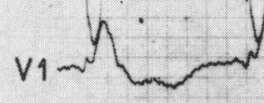

$v_{1} \rightarrow$ VP<smiles>[Al]C1CCC1</smiles>

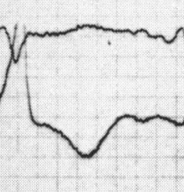

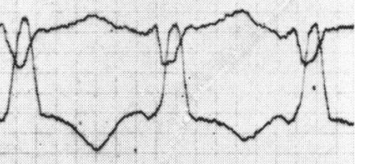
2

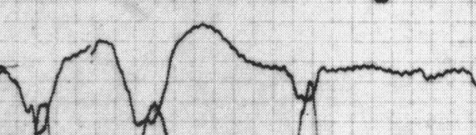
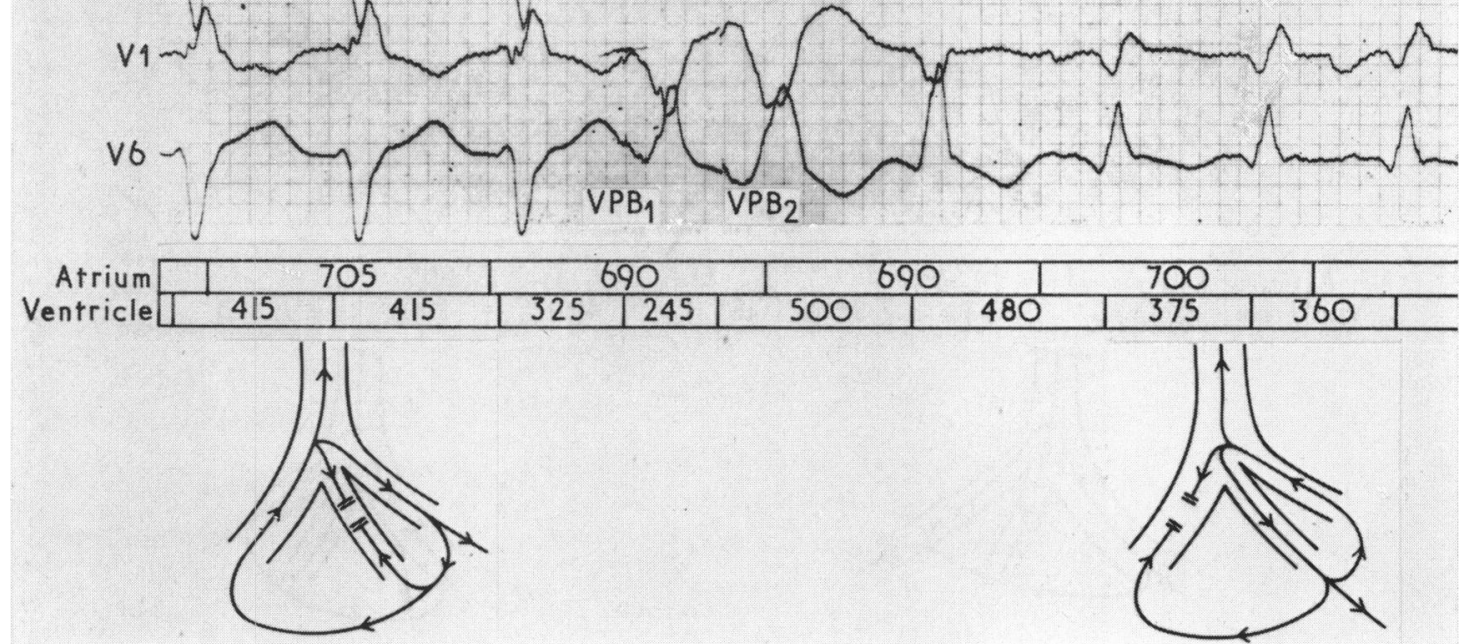

\begin{tabular}{l|l|}
325 & 245 \\
\hline
\end{tabular}

500

\begin{tabular}{l|l|l|l|l}
\hline & \multicolumn{3}{|c|}{700} & \\
\hline 480 & 375 & 360 & \\
\hline
\end{tabular}

\section{FIG. 4 Recording obtained from Case I illustrating the change of the re-entry circuit after two right ventricular premature beats induced during tachycardia.}

\section{Case I}

The initiation of the tachycardia in this patient is illustrated in Fig. I. The first two beats are right ventricular paced beats with a cycle length of $560 \mathrm{msec}$. The third beat is a right ventricular premature beat at a coupling interval of $310 \mathrm{msec}$, and after a delay of $500 \mathrm{msec}$ the tachycardia is initiated. The complexes in tachycardia show right bundle-branch block and left anterior hemiblock. There is complete atrioventricular dissociation as shown by the atrial depolarizations on the high atrial electrogram occurring independently of the ventricular complexes. No His potential is seen before the ventricular complexes on the His bundle electrogram, indicating the ventricular origin of the tachycardia.

The effect of an interpolated premature ventricular beat during tachycardia is shown in Fig. 2. The tachycardia has a cycle length of $420 \mathrm{msec}$. The third beat is a right ventricular premature beat occurring $270 \mathrm{msec}$ after the preceding beat. The interval enclosing this premature beat is $270+540=810 \mathrm{msec}$, which is less than twice the basic cycle length of the tachycardia $(2 \times 420=840)$ so that it is less than compensatory.
A tracing obtained from Case I showing the termination of the tachycardia is shown in Fig. 3. The first three beats of the tracing are the last three beats of the tachycardia. Beats 4 and 5 are stimulated right ventricular premature beats occurring at coupling times of 335 and $225 \mathrm{msec}$, respectively. These two premature beats terminate the tachycardia and the sixth beat is a sinus beat.

A further record showing another effect of interpolated ventricular premature beats during tachycardia is shown in Fig. 4. The first three beats show a pattern of right bundle-branch block and left anterior hemiblock and a cycle length of $415 \mathrm{msec}$. Beats 4 and 5 are right ventricular premature beats and following these premature beats the QRS configuration changes to that of right bundlebranch block and left posterior hemiblock. The cycle length is now shorter at $360 \mathrm{msec}$. A diagram of the possible reciprocal circuit occurring in the bundlebranches is shown below the appropriate QRS complexes in Fig. 4. Our interpretation of this tracing is as follows. During tachycardia with the pattern of right bundle-branch block and left anterior hemiblock the antegrade part of the reciprocal circuit is occurring in the 


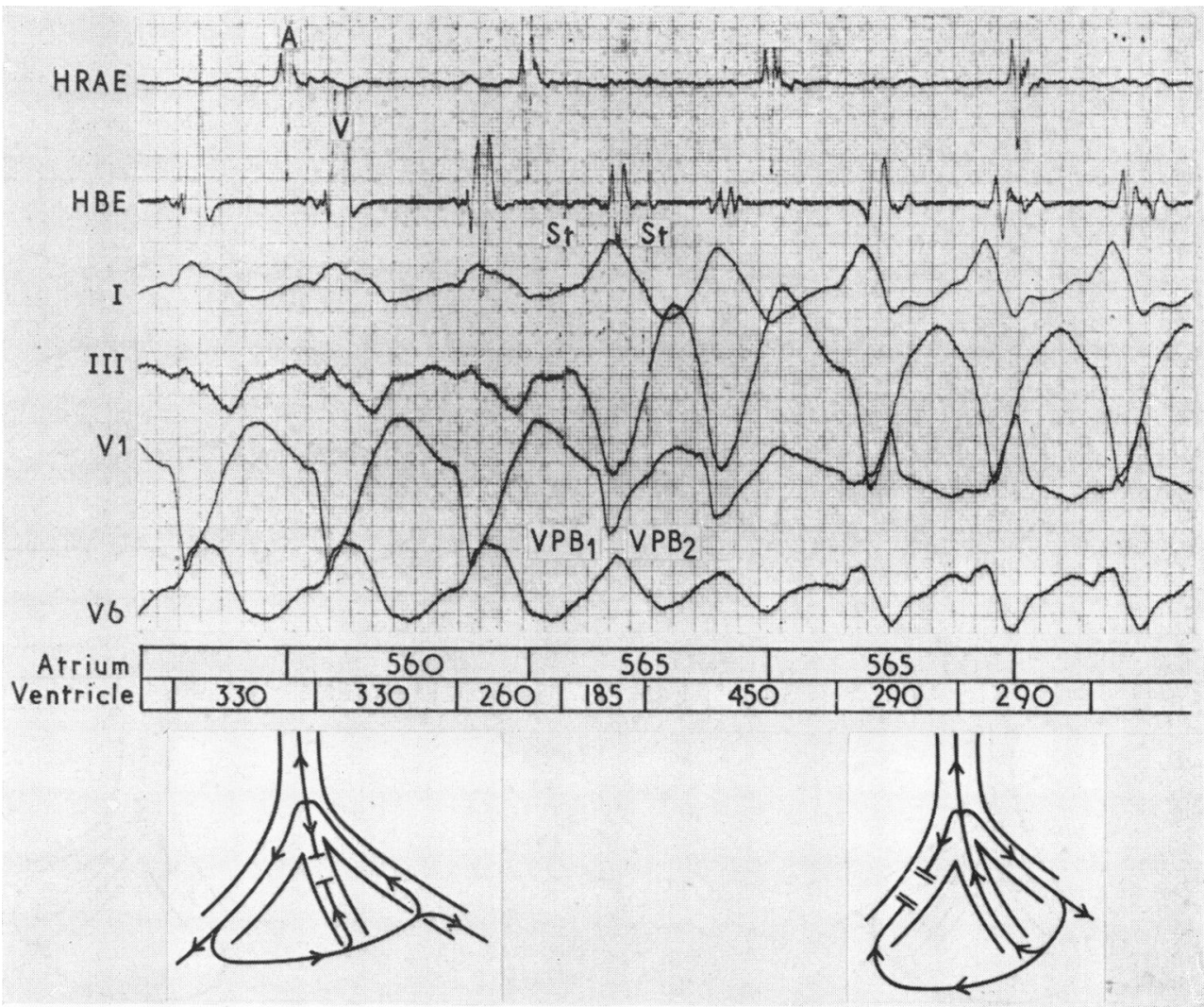

FIG. 5 Recording obtained from Case 2 illustrating the change of the re-entry circuit after two right ventricular premature beats induced during tachycardia.

posterior fascicle of the left bundle and the retrograde pathway is in the right bundle. After the two right ventricular premature beats, the tachycardia is terminated by blocking the right bundle but a further tachycardia is initiated with antegrade conduction in the anterior division of the left bundle and retrograde conduction in the posterior division thus producing a pattern of right bundle-branch block and left posterior hemiblock. The reciprocal circuit is now solely in the left ventricle and the dimensions of the circuit are, therefore, likely to be smaller than when the right bundle is involved, thereby producing the shorter cycle length in tachycardia. The reasons for assuming that the reciprocal mechanism lies in the main bundle-branches are discussed more fully later.

\section{Case 2}

With a basic right ventricular driving cycle length of $600 \mathrm{msec}$ a single right ventricular premature beat with a coupling time of $290 \mathrm{msec}$ could initiate a tachycardia. During tachycardia the QRS configuration showed a pattern of left bundle-branch block and left axis deviation. There was complete atrioventricular dissociation during tachycardia and no His potential preceded the QRS complex, indicating the ventricular nature of the tachycardia. Induced ventricular premature beats during tachycardia were followed by pauses which were less than compensatory. The tachycardia could not be terminated by single or double ventricular premature beats. A tracing demonstrating the effect of two induced ventricular premature beats during tachycardia is shown in Fig. 5. The first three beats show a left bundle-branch block and left axis deviation pattern with a cycle length of $330 \mathrm{msec}$; beats 4 and 5 are induced right ventricular premature beats with coupling times of 260 and 185 msec, respectively. Beats 6,7 , and 8 are part of a continuing ventricular tachycardia but the QRS configuration is now that of right bundle-branch block and left anterior hemiblock. A diagram of the possible reciprocal circuit occurring in the bundle-branches is shown beneath the appropriate complexes in the Figure. In the beats showing the pattern of left bundle-branch block and left axis deviation antegrade conduction is occurring via the right bundle-branch and retrograde conduction via the posterior division of the left bundle. The left ventricle is activated via the posterior division as shown 


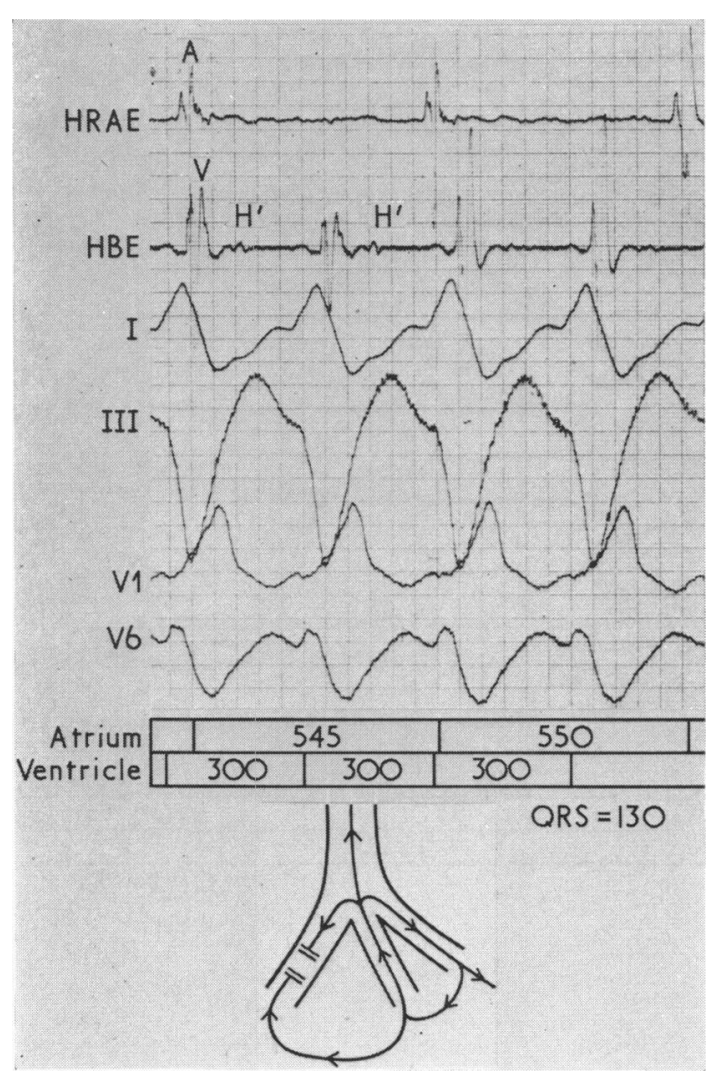

FIG. 6 Recording obtained from Case 2 during tachycardia before the administration of intravenous lignocaine. $Q R S=$ width of $Q R S$ complex in milliseconds.

and the anterior division is blocked thereby producing left axis deviation in the presence of left bundle-branch block. The two right ventricular premature beats lead to block in the right bundle and the tachycardia is terminated. However, the two premature beats initiate a new tachycardia with the pattern of right bundle-branch block and left anterior hemiblock which can be explained by antegrade conduction in the posterior division with retrograde conduction in the anterior division of the left bundle. The reciprocal circuit for the beats with the pattern of left bundle-branch block involves the right and left ventricles, whereas the circuit for the beats with the right bundle-branch block pattern occurs in the left ventricle alone. The dimension of the reciprocal circuit for the beats with right bundle-branch block is therefore smaller, and this is supported by the shorter cycle length of $290 \mathrm{msec}$ for the beats showing the right bundlebranch block pattern as compared to $330 \mathrm{msec}$ for the larger reciprocal circuit producing the beats with the left bundle-branch block pattern.

Further tracings obtained from Case 2 during tachy-

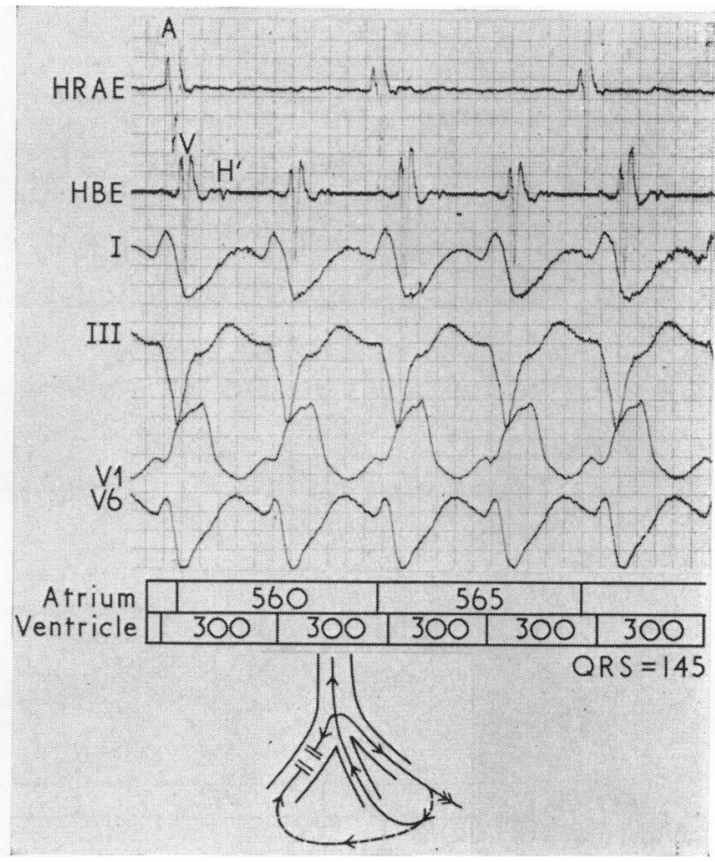

FIG. 7 Recording obtained from Case 2 during tachycardia 40 seconds after the administration of intravenous lignocaine. The increasing delay in ventricular activation in the region of the posterior division of the left bundle is shown by the double arrow.

cardia showing the effect of intravenous lignocaine $100 \mathrm{mg}$ administered at the onset of the series are shown in Figs. 6, 7, and 8. The termination of the tachycardia 90 seconds later is shown in Fig. 8. In Fig. 6 there is a ventricular tachycardia with a cycle length of $300 \mathrm{msec}$ and the pattern of right bundle-branch block and left anterior hemiblock; the QRS width is $130 \mathrm{msec}$. The diagram underneath indicates the reciprocal circuit thought to be involved with antegrade conduction occurring by way of the posterior division of the left bundle and retrograde conduction by way of the anterior division. In Fig. 7 the QRS width has increased to $145 \mathrm{msec}$, and an $S$ wave is beginning to appear in lead $I$ indicating that the frontal plane $Q R S$ axis is swinging to the right; the cycle length is unchanged. In Fig. 8 the QRS width has increased further to $200 \mathrm{msec}$ and the frontal plane axis has swung to the right (deep $S$ in lead $I$ and $R$ in lead III); the cycle length remains unchanged at 300 msec. The tachycardia terminates after the third beat, and the fifth beat is a junctional escape beat. The reason for this axis swing and widening QRS with an unchanging cycle length after intravenous lignocaine is difficult to understand but a possible explanation may be that the bundlebranches involved in the reciprocal circuit have been unaffected by lignocaine, thereby maintaining a constant cycle length, but there has been progressive delay in the 


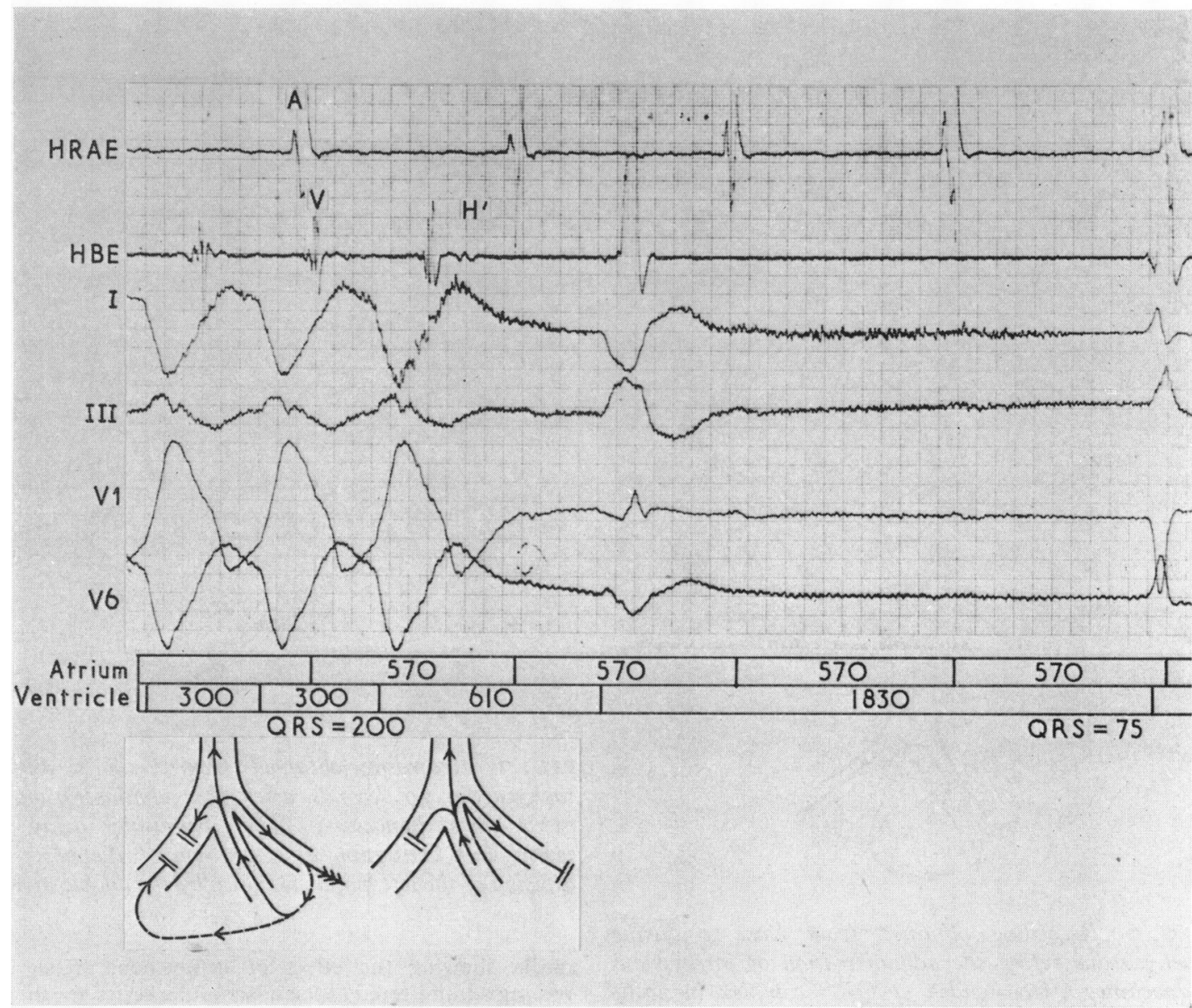

FIG. 8 Recording obtained from Case 2 showing termination of the tachycardia 90 seconds after the administration of intravenous lignocaine. The increasing delay in ventricular activation in the region of the posterior division of the left bundle is shown by the treble arrow.

spread of activation through the ordinary myocardium. This leads to increasing delay in activating the myocardium in the region of the pcsterior division of the left bundle thereby allowing more time for activation of the left ventricle in the region of the anterior division; the frontal plane axis would therefore swing progressively round to the right and the QRS width would increase due to increasing delay in the spread of activation throughout the myocardium. Should the reciprocal pathway itself (i.e. the bundle-branches) be unaffected by lignocaine then no effect on the cycle length of the tachycardia would be expected.

\section{Case 3}

Induced right ventricular premature beats were followed by pauses which were less than compensatory. The tachycardia could be consistently terminated by two induced right ventricular premature beats at coupling times of $165 \mathrm{msec}$ and $150 \mathrm{msec}$, respectively. The mode of initiation of tachycardia by induced right ventricular premature beats could not be studied as the tachycardia was repeatedly restarted by spontaneously occurring ventricular premature beats shortly after it had been terminated by the appropriately timed induced ventricular premature beats. A tracing obtained from Case 3 is shown in Fig. 9. The first two beats have a cycle length of $370 \mathrm{msec}$ and have the QRS configuration of left bundle-branch block and left axis deviation as seen in the tachycardia; no His potential precedes the QRS complex and there is complete atrioventricular dissociation as indicated by the atrial rhythm on the atrial electrograms occurring independently of the ventricular rhythm. These two features indicate the ventricular origin of the tachycardia. The third and fourth beats are induced 


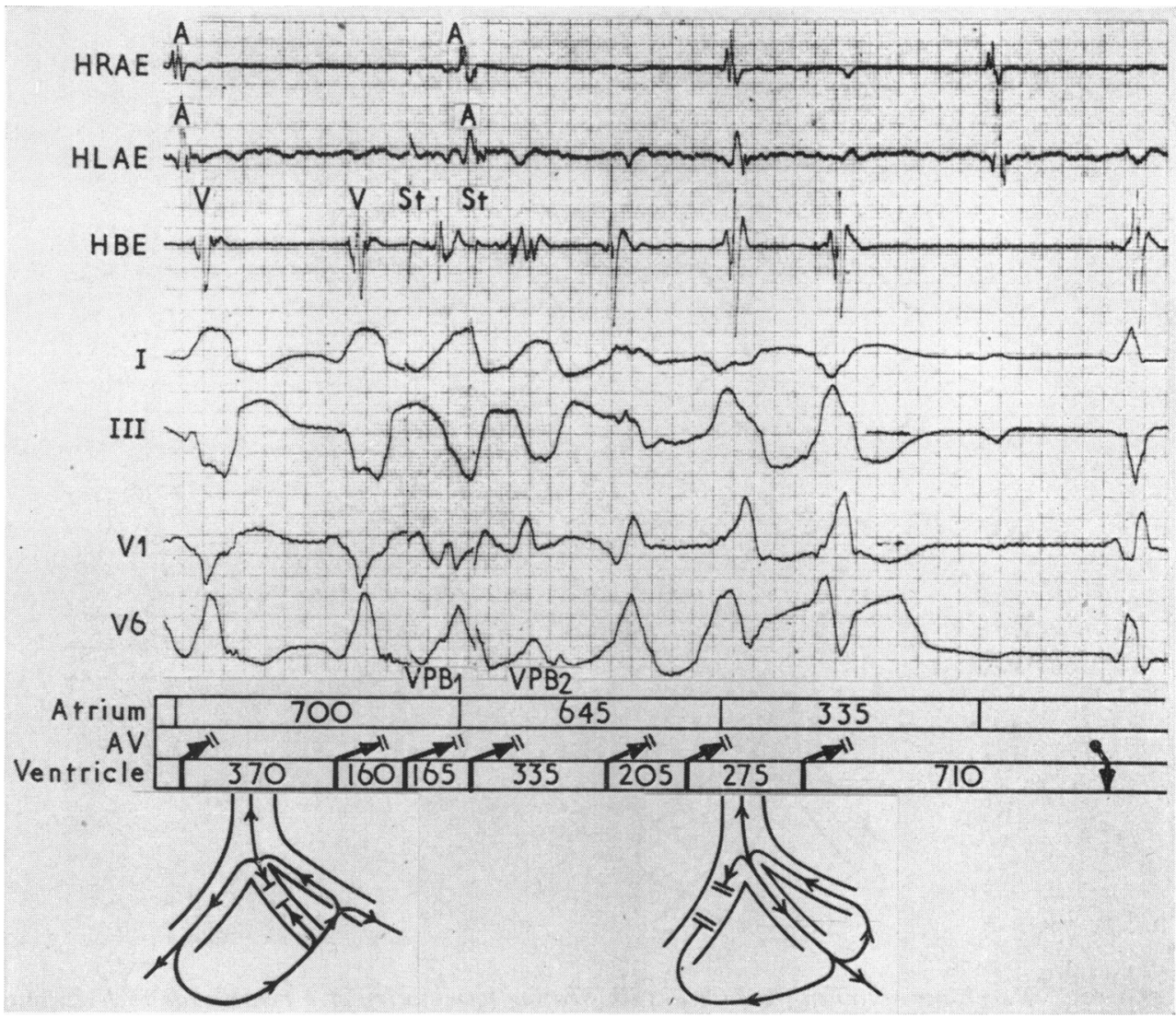

FIG. 9 Recording obtained from Case 3 showing termination of a ventricular tachycardia after two ventricular premature beats which induce a change of the re-entry circuit. AV=atrioventricular junctional region.

right ventricular premature beats and after these two beats the tachycardia continues for a further three beats which now show a pattern of right bundle-branch block and right axis deviation, or left posterior hemiblock; the cycle length is also shorter than for the beats showing the pattern of left bundle-branch block and left axis deviation during the natural tachycardia. The diagrams below the tracing indicate the reciprocal circuits thought to exist for the appropriate ventricular complexes above them. The beats showing left bundle-branch block and left axis deviation pattern can be explained as being produced by a reciprocal circuit in which antegrade conduction is occurring in the right bundle-branch and retrograde conduction in the posterior division of the left bundle with early activation of the ventricular myocardium in the region supplied by the posterior division thereby producing left axis deviation in the presence of left bundle-branch block. The anterior division is blocked as shown. Following the two right ventricular premature beats the right bundle becomes blocked but the tachycardia continues for three more beats showing right bundle-branch block and left posterior hemiblock, which can be explained by a reciprocal circuit involving antegrade conduction in the anterior division of the left bundle with retrograde conduction in the posterior division, the right bundle remaining blocked. The tachycardia then terminates spontaneously and the eighth beat is probably a junctional escape beat.

\section{Case 4}

The tachycardia could be initiated by an induced right ventricular premature beat with a coupling time of 280 msec. Induced right ventricular premature beats during tachycardia were followed by pauses less than compensatory. A tracing obtained from Case 4 is shown in Fig. ro. The first three beats show a ventricular tachycardia with a QRS configuration of right bundle-branch block and left posterior hemiblock. No His potentials preceded the QRS complexes indicating the ventricular origin for the tachycardia. The atrial electrogram shows the presence of atrial fibrillation. The tachycardia has a relatively long cycle length and can be explained on a reciprocal mechan- 


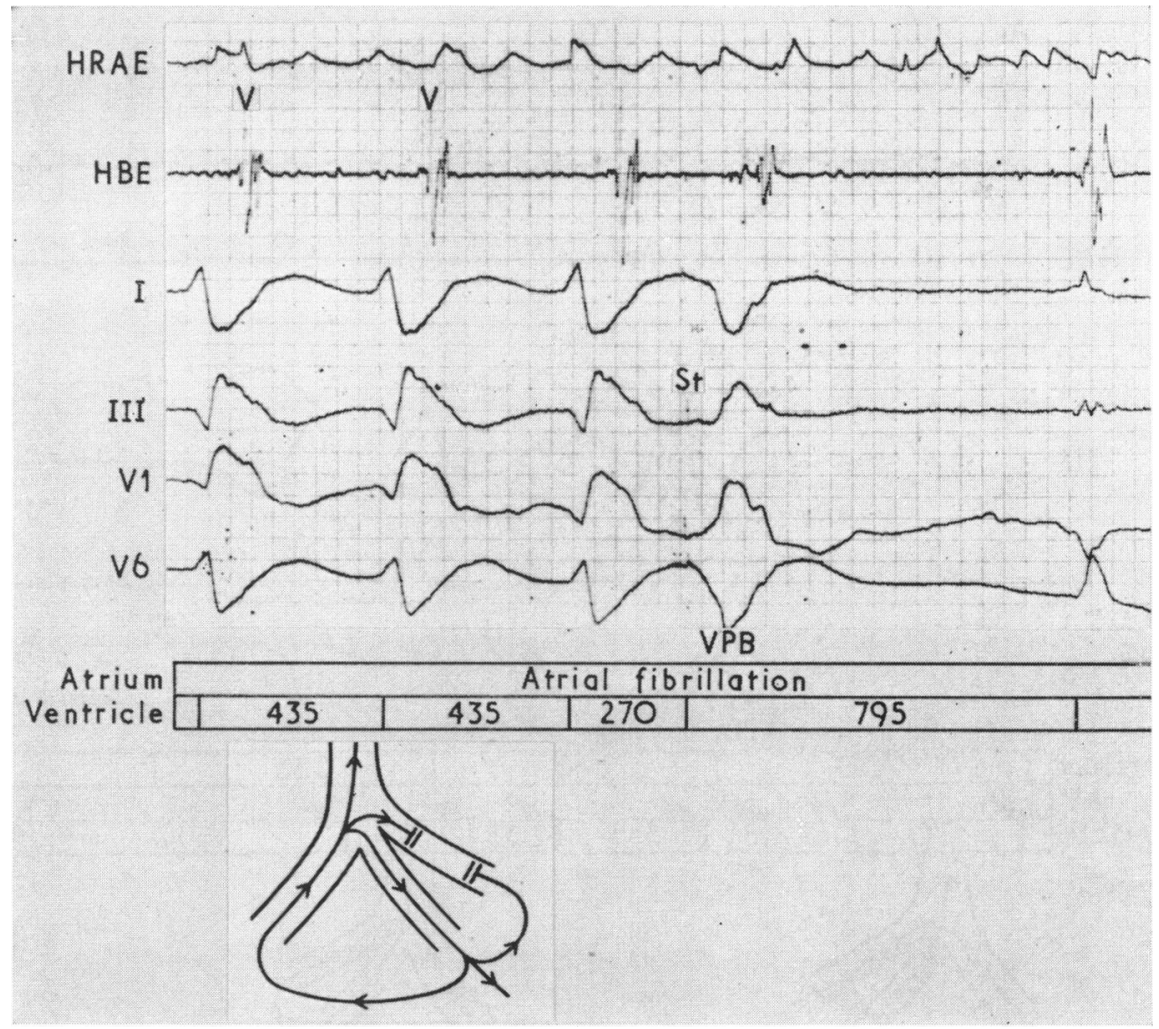

FIG. Io Recording obtained from Case 4 illustrating termination of a ventricular tachycardia by a single right ventricular premature beat.

ism occurring in the bundle-branches with antegrade conduction by way of the anterior division of the left bundle with retrograde conduction in either the right bundle or posterior division of the left bundle. Because of the relatively long cycle length of the tachycardia it was felt that a larger reciprocal circuit might be involved and so the retrograde pathway was thought to be in the right bundle rather than the posterior division of the left bundle. The fourth beat is an induced right ventricular premature beat with a coupling time of $270 \mathrm{msec}$. The tachycardia is terminated by this premature beat and the fifth beat is the first beat of the supraventricular rhythm.

\section{Discussion}

Much discussion has centred around the mechanisms underlying tachycardias. The two main mechanisms postulated are that the tachycardia is due to a rapidly discharging focus or that some form of re-entry mechanism is responsible. Lown, Kleiger, and Williams (1965) have shown that a ventricular tachycardia can develop in the overdigitalized dog's heart and have suggested that this is due to the development of an increased rate of discharge from the cardiac cells. Scherf et al. (1963) believed that a rapidly discharging focus could develop in the atrioventricular node following a single atrial or ventricular premature beat in the human heart.

Cranefield, Klein, and Hoffman (I97I) showed that depressed conduction velocity in excised bundles of canine Purkinje fibres could lead to the development of re-entry within these short segments. Sasyniuk and Mendez (197I) demonstrated in the isolated canine papillary muscle that premature stimulation could lead to single or double reentry in the terminal Purkinje fibres. Re-entrant activity leading to isolated ventricular extrasystoles or sustained ventricular tachycardia following premature stimulation of the atria was shown by Wallace and Mignone (1966) in the intact hearts of open chested dogs after cooling of a focal area of ventricle. Similarly, Han, Goel, and Hanson (1970) described single re-entrant beats and a re-entrant ventricular tachycardia in the ischaemic dog heart and showed that an essential part of this mechanism 
was the slowing of conduction within the ischaemic area after premature ventricular stimulation, thereby allowing recovery of adjacent non-ischaemic myocardium in time for it to be re-excited. This slowing of conduction within an ischaemic area leading to re-entry has also been shown in the human heart at open heart surgery (Cox et al., 1969).

In the study of supraventricular tachycardia three criteria have been used in support of a reciprocal mechanism as the basis for the tachycardia (Wellens, 197I). First, the tachycardia can be initiated by a suitably timed atrial or ventricular premature beat. Secondly, induced premature beats during tachycardia are followed by pauses less than compensatory, and, thirdly, the tachycardia can be terminated by suitably timed atrial or ventricular premature beats. In the dog heart the initiation of a re-entry ventricular tachycardia by a single ventricular premature beat has been described by Han et al. (1970). Wellens et al. (1972) showed that five patients with paroxysmal ventricular tachycardia also fulfilled the three criteria described above which he had applied to the diagnosis of a re-entry mechanism in supraventricular tachycardia; and he therefore considered that a re-entry or reciprocal mechanism was likely to be responsible for the ventricular tachycardia in these five patients. He postulated four different sites in the ventricles where the re-entry circuit could occur.

In each of the four patients with ventricular tachycardia described in this paper, the tachycardia was initiated by a suitably timed ventricular premature beat; ventricular premature beats induced during tachycardia were followed by pauses less than compensatory, and in Cases I, 3, and 4 the tachycardia could be terminated by suitably timed ventricular premature beats. This response to induced ventricular premature beats is most easily explained on the basis of a re-entry mechanism causing the ventricular tachycardia. Further evidence for this is illustrated in Cases $I, 2$, and 4 by the long intervals between the ventricular premature beat initiating the tachycardia and the first ventricular beat of the tachycardia. These intervals are longer than the cycle lengths of the tachycardias and indicate prolonged conduction times during the initiation of the tachycardias, one other criteria necessary for re-entry to occur (Han et al., I970).

Figures 4, 5, and 9 were obtained during tachycardia and show gross changes in QRS configuration as a result of inducing right ventricular premature beats; the cycle length of the tachycardia before and after the premature beats also changes. If the reentry circuit was in the terminal Purkinje system then the re-entry circuit would be small and any changes in direction of the circulating impulse would be unlikely to produce a significant change in QRS configuration on the surface electrocardiogram, because the activation process of the ventricle would probably be very similar from a re-entry circuit confined to the terminal Purkinje fibres irrespective of the direction of the circulating impulse within this circuit. If the terminal Purkinje fibres were responsible for the re-entry mechanism, then a gross change in QRS configuration as a result of ventricular premature stimulation during tachycardia could only be explained on the basis of a completely new re-entry circuit coming into action in the ventricles some distance from the first site. If the re-entry circuit lies in the main bundle-branch system, however, rather than the terminal Purkinje system then a change in direction of the circulating impulse with or without a change in the bundlebranches involved would be expected to produce a gross change in the QRS configuration on the surface electrocardiogram as the activation process of the ventricle would be radically changed. This possibility is illustrated in the diagram of the reentry circuits within the bundle-branches shown below the appropriate QRS complexes in Figs 4, 5, and 9.

Retrograde conduction in a bundle-branch can

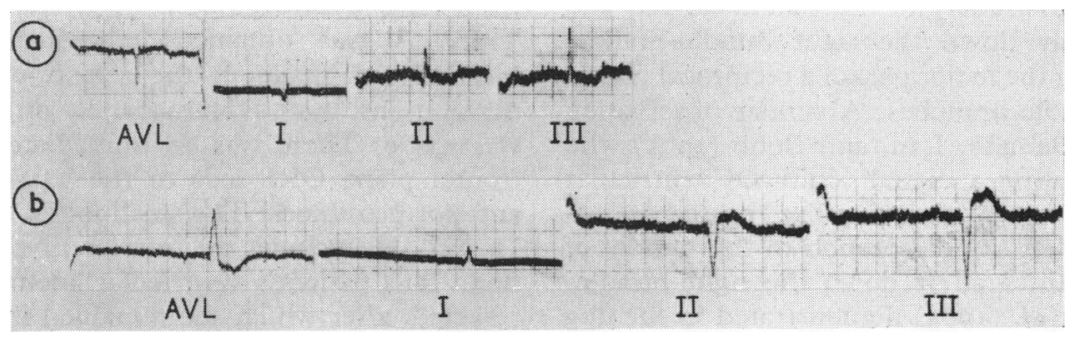

FIG. II Surface electrocardiogram obtained from Case 3 taken before section of the anterior radiation of the left bundle (trace $A$ ) and immediately after section (trace $B$ ). 

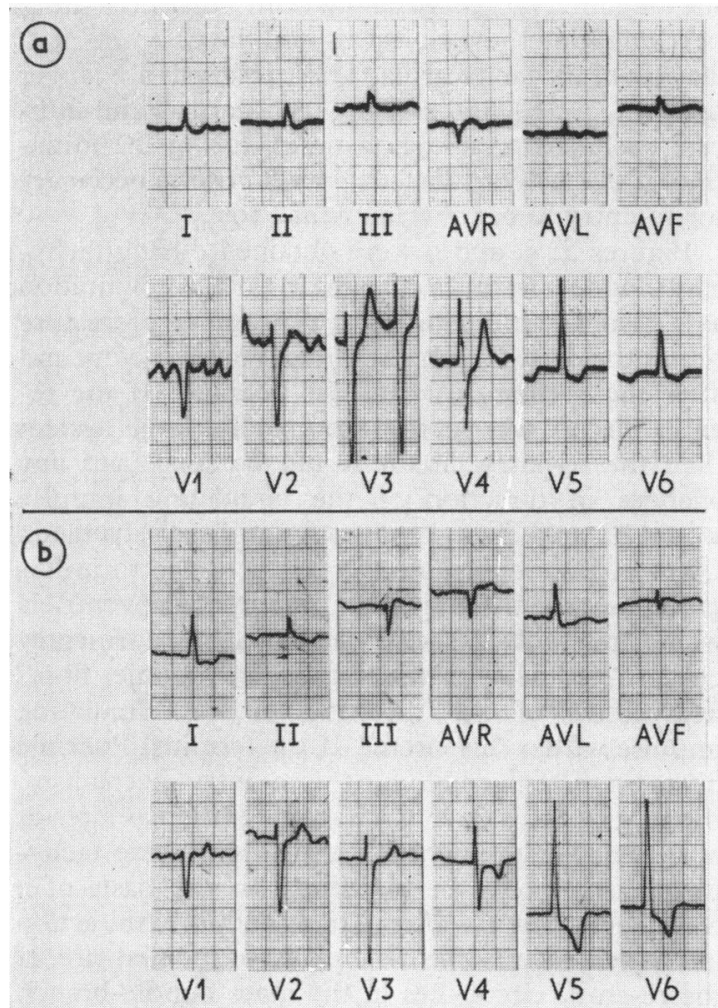

FIG. I2 Surface electrocardiogram obtained from Case 4, preoperatively (trace $A$ ) and postoperatively (trace B).

occur and has been shown in the dog heart by Moe, Mendez, and Han (1965). The clinical counterpart of this has been reported by Wellens and Durrer (1968). Janse (197I) has shown that right ventricular stimulation can be followed by passage of the impulse through the myocardium leading to retrograde invasion of the left bundle-branch and passage of the impulse retrogradely to the bundle of His and then antegradely down the right bundle-branch, thus completing the major part of a reciprocal circuit within the bundle-branches. A similar observation was made by Damato, Lau, and Bobb (197I) who showed that during a digitalis-induced ventricular tachycardia in dogs the impulse passed retrogradely in the left bundle-branch to the bundle of His and then antegradely down the right bundlebranch. Moe et al. (1965) demonstrated in the dog heart the occurrence of a His bundle echo after antegrade conduction in the left bundle-branch and then retrograde invasion of the right bundle-branch.
On the basis that an impulse can travel retrogradely in one bundle-branch and activate another bundle-branch via the bundle of His we postulate that the gross changes in QRS morphology produced by ventricular premature beats in the patients described in this paper are best explained on the basis of a re-entry mechanism within the main bundle-branches rather than the terminal Purkinje system.

In Case 3 a large swing to the right in the mean frontal plane $Q R S$ axis occurred after the administration of lignocaine. It is unlikely that this represents a change in the reciprocal circuit, and we think it is due to increasing delay in the spread of activation through the ordinary myocardium, the reciprocation continuing unaltered in the main bundlebranch system both before and during termination of the tachycardia with lignocaine. Bekheit et al. (1973) have shown that clinically lignocaine has little effect on conduction times in the His Purkinje system as shown by constant His to onset of ventricular (HV) activation times before and after the administration of lignocaine.

If the main bundle-branches are involved in the manner described, then interruption of any part of the re-entry circuit should terminate the tachycardia. Cases 3 and 4 both had drug resistant tachycardias recurring shortly after numerous conversions to sinus rhythm by DC shock. Both patients required emergency operation in an attempt to improve their haemodynamic state. Case 3 required resection of a left ventricular aneurysm and Case 4 a mitral valve replacement and saphenous vein bypass graft. From Fig. 9 and 10, illustrating the re-entry circuit thought to be involved in the tachycardia, it will be seen that in both patients the anterior division of the left bundle formed the antegrade part of the circuit. It was, therefore, decided to attempt to interrupt the anterior radiation of the left bundle during open heart surgery in these two patients, and a $1.5 \mathrm{~cm}$ long incision was made in the septum in the region of the anterior radiation of the left bundle in each patient. A surface electrocardiogram obtained from Case 3 during operation is shown in Fig. II. Trace A was obtained immediately before an incision was made in the region of the anterior division and trace $B$ immediately after the incision was made. There was an immediate swing in the frontal plane QRS axis to the left producing left anterior hemiblock. The small initial $\mathrm{r}$ wave in leads II and III excludes an inferior myocardial infarction. This patient's ventricular aneurysm was then resected, after which she remained in normal sinus rhythm with left anterior hemiblock but adequate ventricular function could not be obtained and she succumbed. The surface electrocardiogram of Case 
4 is shown in Fig. 12. Trace A was obtained preoperatively and trace $B$ after mitral valve replacement and an incision in the region of the anterior division of the left bundle. Postoperatively the frontal plane QRS axis has swung to the left (qR pattern in lead III becoming an rS pattern). True left anterior hemiblock has, however, not been produced. This patient has remained well and free from tachycardia. The improvement in this patient's haemodynamic state after mitral valve replacement and saphenous vein bypass graft might well have been sufficient in itself to prevent further bouts of ventricular tachycardia. Section of the anterior radiation of the left bundle, however, adds very little to the operating time and if our deductions concerning the re-entry circuit are correct then this procedure could be a valuable new surgical therapeutic approach to patients with intractable life threatening ventricular tachycardia. Resection of a ventricular aneurysm in the management of ventricular tachycardia is well recognized (Thind, Blakemore, and Zinsser, 197I) and it may be that a re-entry circuit exists in the region of the aneurysm. This does not preclude the re-entry circuit occurring in the main bundle-branches, as the presence of an aneurysm may lead to distortion of the bundlebranch system to a degree sufficient to allow abnormal conduction and re-entry to occur.

This work was supported by a British Heart Foundation Grant. We would like to thank Mr. Alan Yates who operated on three of the patients.

\section{References}

Adams, C. W. (1962). Functional paroxysmal ventricular tachycardia. American fournal of Cardiology, 9, 215.

Bekheit, S., Murtagh, J. G., Morton, P., and Fletcher, E. (1973). Effect of lignocaine on conducting system of human heart. British Heart fournal, 35, 305.

Cooke, W. T., and White, P. D. (1943). Paroxysmal ventricular tachycardia. British Heart fournal, 5, 33.

Cox, J. L., Daniel, T. M., Sabiston, D. C., and Boineau, J. P. (1969). Desynchronized activation in myocardial infarction - a re-entry basis for ventricular arrhythmias. Circulation, 39, Suppl. 3, 63 .

Cranefield, P. F., and Hoffman, B. F. (1971). Conduction of the cardiac impulse; II. Summation and inhibition. Circulation Research, 28, 220.
Cranefield, P. F., Klein, H. O., and Hoffman, B. F. (I97I). Conduction of the cardiac impulse; I. Delay, block, and one-way block in depressed Purkinje fibres. Circulation Research, 28, 199.

Damato, A. N., Lau, S. H., and Bobb, G. A. (1971). Digitalisinduced bundle-branch ventricular tachycardia studied by electrode catheter recordings of the specialized conducting tissues of the dog. Circulation Research, 28, 16.

Hair, T. E., Eagan, J. T., and Orgain, E. S. (I962). Paroxysmal ventricular tachycardia in the absence of demonstrable heart disease. American fournal of Cardiology, 9, 209.

Han, J., Goel, B. G., and Hanson, C. S. (1970). Re-entrant beats induced in the ventricle during coronary occlusion. American Heart fournal, 80, 778.

Janse, M. J. (197I). The effect of changes in heart rate on the refractory period of the heart. Amsterdam, Thesis: Mondeel-Offsetdrukkerij.

Lewis, T. (1909). Single and successive extrasystoles. Lancet, I, 382.

Lown, B., Kleiger, R., and Williams, J. (1965). Cardioversion and digitalis drugs. Changed threshold to electric shock in digitalized animals. Circulation Research, 17, 519.

McGee, R. R., and Tullis, I. F. (1959). Ventricular tachycardia. American fournal of Cardiology, 3, 300.

Moe, G. K., Mendez, C., and Han, J. (1965). Aberrant A-V impulse propagation in the dog heart. A study of functional bundle branch block. Circulation Research, 16, 261.

Sasyniuk, B. I., and Mendez, C. (I97I). A mechanism for reentry in canine ventricular tissue. Circulation Research, 28, 3.

Scherf, D., Cohen, J., Parangi, A., and Yildiz, M. (1963). Paroxysmal tachycardia precipitated by atrial or ventricular extrasystoles. American fournal of Cardiology, II, 757.

Scherlag, B. J., Lau, S. H., Halfant, R. H., Berkowitz, W. D., Stein, E., and Damato, A. N. (1969). Catheter technique for recording His bundle activity in man. Circulation, 39, I3.

Thind, G. S., Blakemore, W. S., and Zinsser, H. F. (I97I). Ventricular aneurysmectomy for the treatment of recurrent ventricular tachyarrhythmia. American fournal of Cardiology, 27, 690 .

Wallace, A. G., and Mignone, R. J. (1966). Physiologic evidence concerning the re-entry hypothesis for ectopic beats. American Heart fournal, 72, 60.

Wellens, H. J. J. (1971). Electrical Stimulation of the Heart in the Study and Treatment of Tachycardias, p. 14. H. E. Stenfert Kroese N.V. Leiden.

Wellens, H. J. J., and Durrer, D. (I968). Supraventricular tachycardia with left aberrant conduction due to retrograde invasion into the left bundle branch. Circulation, 38, 474.

Wellens, H. J. J., Schuilenburg, R. M., and Durrer, D. (1972). Electrical stimulation of the heart in patients with ventricular tachycardia. Circulation, 46, 216.

Requests for reprints to Dr. R. A. J. Spurrell, Cardiac Department, Guy's Hospital, London SEI 9RT. 